\title{
The Right to Teach in a Hyper-Digital Age: Legal Protections for (Post-)Pandemic Concerns
}

\author{
Mathieu Deflem ${ }^{1}$ \\ Accepted: 3 May 2021 / Published online: 28 May 2021 \\ (C) Springer Science+Business Media, LLC, part of Springer Nature 2021
}

\begin{abstract}
The development of the internet has presented special challenges for teaching and learning, especially from the viewpoint of the rights and expectations of the instructor to maintain an environment appropriate to fulfill educational objectives. Restrictions imposed during the COVID-19 pandemic have amplified these concerns as virtual teaching methods almost literally overnight had to be adopted very widely among instructors. Among the ironies have been several instances where recorded (fragments of) lectures delivered virtually were publicized on social networking sites for reasons of exposing some perceived form of objectionable content. In this paper, I focus on the policy implications of lectures being transmitted on the internet subject to their recording and distribution in ways not authorized by the instructor, especially from the viewpoint of rights formally granted in the US legal system. Various legal avenues are available to protect lectures, specifically in relation to copyright law, academic freedom, and contractual breach of trust. Although pedagogical goals and means must always remain primary in our teaching, these legal measures can be relied upon when other safeguards fail in order to maintain and promote educational integrity.
\end{abstract}

Keywords Academic freedom $\cdot$ Breach of confidence $\cdot$ Copyright $\cdot$ Virtual instruction $\cdot$ Teaching

\section{Teaching in an Age of High Technology}

The spoken word is in need of protection to fulfill its intent to persuade in thought and action. As one special form of speech, teaching primarily rests on authority on the basis of acquired expertise, but whether such authority will be more or less favorably and successfully achieved depends not only on the abilities and willingness of instructors and students to respectively teach and learn, but also on the cultural and technological conditions under which education is organized. In today's age, there is perhaps no force greater to have shaped teaching than the changes brought about by the development of the information age and, in particular, the internet.

From the 1990s onwards, the internet has been used to develop distance education or virtual instruction programs, which have been slowly but steadily adopted by our everexpanding colleges and universities. The COVID-19 pandemic catapulted virtual teaching as the near-exclusive method of

Mathieu Deflem

Deflem@mailbox.sc.edu

1 Department of Sociology, University of South Carolina, 911 Pickens Street, Columbia, SC 29208, USA instructional delivery, first during the Spring of 2020 when face-to-face teaching was abruptly halted and, subsequently, throughout the 2020-2021 academic year. Although the physical classroom will surely regain a prominent place in education after the pandemic will have subsided, it is also clear that online education is here to stay.

Conditions specific to online teaching, particularly the use of streaming technologies, have exposed novel challenges to the rights and responsibilities of the instructor. Especially noteworthy have been cases where the instructor's teaching within a particular educational setting was exposed to certain vulnerabilities as students (and sometimes even others not formally registered for a class) were able to record lectures and spread their content, often highly selectively, on social networking sites, motivated by reasons far removed from any educational objectives (e.g., Flaherty 2020; Miller 2020; Steinbuch 2021). These interferences typically involved public exposures in relation to some statements by the instructor that were judged to be objectionable or cause harm. While such perceived harm may be real (Cohen 2017), so too are the consequences of publicity experienced by the instructor.

Besides tribulations from unwanted attendants "bombing" online lectures and parents desperately trying to find effective ways to help their children learn in the virtual days of the 
COVID-19 pandemic (Conklin 2020), instructors at schools and universities potentially face even more problems than already are presented in today's so-called cancel culture whereby anything they say during lectures may be (mis)used in unintended ways beyond their control. These challenges are peculiar but not altogether new. Some 20 years ago, during the early days of the internet in the late 1990s, online lecture notes companies were among the first industries in the e-commerce sphere to take advantage of the internet to distribute lecture notes and other course content without the instructor's consent (Deflem 2000). But those days still assumed a primacy of face-to-face lectures in the setting of a physical classroom. The conditions posed by the COVID-19 pandemic have rapidly accelerated relevant concerns with the ubiquitous use of online teaching, bringing out the challenges associated with teaching in the internet age more and more acutely than before.

In this paper, I address legal avenues that can be relied upon within the framework of US law to secure the rights of the instructor in the contemporary (post-)pandemic teaching environment. Although not exclusively a matter affecting universities, my observations are especially geared towards the conditions that exist in institutes of higher learning. Lest this effort be misunderstood, this legal focus can be valid only on the basis of the Weberian insight that the internal perspective of law (as a formal system of rules) is to be differentiated from the external study of law (as an observable phenomenon) and related normative considerations (of law as justice) (Deflem, 2008, pp. 4-5). Especially in an article written by a sociologist for a social-science audience, it should be clear that any reliance on law as an instrument does not invalidate the insights on the limits of law as a social reality which other, non-legal perspectives can gain concerning the function and consequences of law in society. The legal quest for efficiency with respect to rules and their implementation cannot substitute for the need for an analysis of legal facts and an evaluation of relevant norms. But one should also not overlook that in a highly rationalized society such as our own, questions of law are inevitably among the central questions of society.

The value of teaching needs no justification. And transformations of education affect us all. Because of the serious consequences that may result from public exposures of and accusations against instructors, especially on popular social networking sites, it stands to reason to analyze if and how a legal framework can be developed as an effective instrument to protect the dignity of student-teacher interactions which we value from an educational viewpoint. A legal focus on teaching can only be justified on the understanding that the relationship between instructor and student should primarily be regulated in a pedagogically appropriate manner. As responsibly educated teachers we ought to be mindful that teaching is and should first and foremost be pre-contractually regulated through mutual trust in a respectful environment of education.
The here developed legal framework can be relied upon to safeguard the rights of the instructor when judged both appropriate and necessary. The application of legal measures in the online teaching environment should only occur when trust has broken down and no other recourse is available. During the COVID-19 pandemic (and before), instructors and education administrators have already begun to realize such legal necessities and their impact on instructors and the institutions in which they are employed (Bultman 2020; Hutchinson 2003; Vincent 2020).

The focus of this paper is on legal provisions that apply in USA, although the discussed principles and measures might be extended to other jurisdictions as well, albeit in more or less altered form. Among the effective legal measures in the American context, I will explain, formal policies to protect the rights of the instructor can be developed in terms of copyright, academic freedom, and breach of confidence.

\section{Law and Teaching: a Brief History}

In the Anglo-American tradition, the relevance of law in matters of teaching has been recognized for a long time. Dating back to the early nineteenth century, legal provisions have been developed in relation to the rights and duties of teachers and their students in the setting of a classroom, the fundamental premises and principles of which still, though differently, apply today.

The earliest instance to discuss lectures in a legal context involved an English court case, Abernethy v. Hutchinson (1825), in which a surgeon named Abernethy brought action against defendants Hutchinson, Knight, and Lacey, who had published some of Abernethy's medical lectures in the journal The Lancet. Arguing that lectures can be considered in terms of property or as a matter of trust between teacher and students, the presiding judge decided to rule on the matter of trust and held that there was an "implied contract" between the students and their teacher (Abernethy, p. 1315). The students who had taken lecture notes and sold them for profit, the judge argued, should therefore be held liable "on the ground of breach of contract or of trust" (p. 1317). Students attending the lecture could take notes "only for the purposes of their own information," but were "not justified in publishing them for profit" (p. 1313).

The Abernethy case has served as precedent in several later court cases in the USA (e.g., International News Service v. The Associated Press 1918; Miles Medical Company v. Park \& Sons 1911). In Sherrill v. Grieves (1929), the first case specifically dealing with lectures before a US court, the Supreme Court of the District of Columbia held that an instructor who taught for United States Army officers held a copyright to his lectures. When US military authorities had printed a pamphlet incorporating the instructor's teachings, 
the court ruled that the teacher, not his employer, owned the copyright to the lectures because he was not obliged to reduce his lectures to writing as part of his employment.

Since the days of Abernethy, various court cases in the USA have continued to uphold the copyright of lectures and oral presentations. In 1959, the US Supreme Court in Public Affairs Associates Inc. v. Rickover (1962) held that Vice Admiral Rickover owned the copyright to speeches he had delivered, even though those speeches were part of his work for the Navy. Likewise, in King v. Mister Maestro (1963), Martin Luther King successfully moved for a preliminary injunction restraining 20th Century Fox Record Corporation from selling phonograph records of his famous "I Have a Dream" speech and from otherwise infringing on King's copyright of the speech.

The most important case that secured copyright to lectures in colleges and universities until today is Williams $v$. Weisser (1969). The case involved a suit against the company Class Notes, a commercial provider of lecture notes, which had been selling notes of a course taught by a UCLA anthropology professor. When the professor objected to the lecture notes of his class being copied and sold by the company, he sought permanent injunction and damages. Relying on several prior legal cases, including Abernethy (Williams, pp. 736-740), the court judged in the professor's favor on the grounds that the he held copyright to his lectures and, additionally, that his privacy had been violated by the public use of his name (p. 730). On appeal to the case, the higher court affirmed the lower court ruling and held that the teacher owned the copyright to his lectures, arguing that oral delivery of lectures in a classroom is not a general, but only a limited publication for the registered students (p. 741).

\section{Establishing the Copyright of Teaching}

Legislation and jurisprudence on copyright in the USA is complicated by historical changes in relevant federal law (Nimmer and Nimmer 1978). Until 1976, the USA had a dual system of federal copyright law, specified in the Copyright Act of 1909 under Title 17 of the US Code, which granted copyright protection to all original writings by an author, among which the 1909 Act explicitly listed "lectures, sermons, addresses (prepared for oral delivery)" (Copyright Act of 1909). While common law applied before publication, federal copyright regulated works after publication.

In 1976, US Congress introduced a new Copyright Act that made federal copyright applicable from the moment of creation, not the later moment of publication, of any work within the scope of the statute. The moment of creation was determined by fixation of a work in a tangible medium of expression "when its embodiment in a copy or phonorecord, by or under the authority of the author, is sufficiently permanent or stable to permit it to be perceived, reproduced, or otherwise communicated for a period of more than transitory duration" (Copyright Act of 1976, Title $17 \S 102$ ). The 1976 Act explicitly took into account the potential development of new media of data storage by extending copyright to all "original works of authorship fixed in any tangible medium of expression, now known or later developed" (ibid.).

In relation to copyright law on matters of education, an important question is whether the teaching and other works created by an instructor as an employee of a school belong to the instructor as author or to the school as employer. The query relates to the fact that the 1976 Act specified a socalled work-for-hire provision, which holds that a "“work made for hire' is; (1) a work prepared by an employee within the scope of his or her employment; or (2) a work specially ordered or commissioned... if the parties expressly agree in a written instrument signed by them that the work shall be considered a work made for hire" (Title 17 § 101).

There is wide agreement among legal experts that a teacher exception to the work-for-hire provision is implicitly guaranteed by the 1976 Act (Borow 1998; Dreyfuss 1987; Holmes and Levin 2000; Le Moal-Gray 2016; Meyer 1998; VerSteeg 1990, 1996). The position of an implied teacher exception to the 1976 Copyright Act is defended because the federal law was not enacted to surpass the 1909 Act, but was instead meant to deepen and explicate the prior provision. As such, because under the 1909 Act the work-for-hire doctrine was explicitly not held applicable to teachers, it follows that the principle of a teacher exception is maintained (Nimmer and Nimmer 1978; Dreyfuss 1987; VerSteeg 1990; Meyer 1998). A related argument stems from the fact that not accepting a teacher exception to the work-for-hire provision would create undesirable consequences. As VerSteeg (1990, p. 408) argues, it cannot make sense to give teaching copyrights to universities because teachers moving from one school to another would otherwise not be permitted to use course materials they had developed at a prior school. Likewise, Dreyfuss (1987, p. 603) relies on principles of academic freedom and the tradition of professional authorship in the academia to conclude that employer authorship in the university is a fiction.

Several courts have accepted and applied the teacher exception to the work-for-hire doctrine. In Williams v. Weisser (1969), for instance, the judge argued that the copyright of lectures belongs to the teachers, because "[p]rofessors are a peripatetic lot, moving from campus to campus. The courses they teach begin to take shape at one institution and are developed and embellished at another" (pp. 734-735). In Hays $v$. Sony Corporation of America (1988), the court similarly acknowledged the teacher exception and used an undesirable consequences argument, referring to the "havoc" that would 
be created if the exception was not accepted, additionally pointing out "the absence of any indication that Congress meant to abolish the teacher exception" (Hays, p. 416).

The discussion on the teacher exception to copyrighting is useful in the present context because the debate implies that instructors' works are copyrighted, the only question being who owns the right. A related question then is if the copyrightable works produced by teachers and professors in educational institutions include their lectures. The 1976 Copyright Act explicitly does not grant copyright to "any idea, procedure, process, system, method of operation, concept, principle, or discovery, regardless of the form in which it is described,

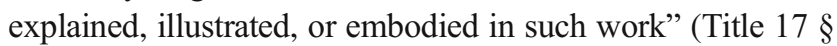
102) but only to certain forms in which facts and ideas are presented (Needham et al. 1998, p. 219). To determine copyright protection under federal law, therefore, a distinction must be made between the form in which a statement is expressed and the idea of the expression. Since the 1976 Act assigns copyright only to works fixed in a tangible medium of expression, orally expressed ideas as such cannot be federally copyrighted. However, this does not mean that all such expressions are exempt from copyright protection. In the Arica (1991) decision, the Supreme Court already argued that federal copyright "protects an author's particular expression of an idea" (Arica, p. 1062, my emphasis).

There are reasonable grounds to argue that the lectures delivered by instructors in educational institutions are copyrighted on the grounds that they are by their very nature always, in the language of the 1976 Act, a specific and fixed form of expression. The copyrightability of educational lectures can be defended taking into account the provisions of the 1976 Act on the status of ideas and facts, on the one hand, and the nature of lectures, on the other. Educational lectures are granted copyright because they are, by their very nature, specific expressions that cannot be dissociated from the particular form in which they are delivered. Lectures in educational settings, especially those conducted by qualified instructors at accredited institutes of (higher) learning, are never mere oral expressions as such, but are always prepared and delivered in a specific form with specific objectives geared towards a specific audience.

Additionally contributing to their fixed nature, educational lectures typically also include various accompanying materials, such as prepared notes from which teachers lecture orally, written text on blackboards and over-head projectors, selected images and sound recordings, maps and lesson plans, accompanying internet resources, and textbooks and other scholarly writings on which lectures are based. This notion was already expressed in Abernethy (1825), where the judge observed that the teacher had written down "a great mass of writing" for his teaching and that his lectures "though not verbatim the same as his notes and writings, yet were in substance, arrangement, and statement of the facts, substantially the same" (p. 1315). To conceive of a lecture in an educational institution as a mere oral delivery of ideas and opinions is readily counter-intuitive to any sound conception of academic teaching.

In sum, it makes sense to accept the court's argument in Williams $v$. Weisser (1969) that "[u]niversity lectures are sui generis," i.e., expressions of a specific kind (p. 735). The physical or virtual classroom in an institute of learning is not a forum of participatory democracy but a purposively designed setting with a particular functionality and division of labor. The key to teaching is not a transmission of mere information, but of communicating knowledge that is appropriate relative to specified educational objectives. In the Williams (1969) case, this idea was expressed in terms of "a distinction between what is taught and how it is taught," arguing that the key issue is "the concrete form" in which instructors teach a subject matter "for pedagogical purposes" (p. 732).

Lectures recorded by means of video technologies and/or transmitted over the internet enjoy even more concrete copyright because of their distinct fixed form, a right that belongs to the instructor, not the educational institution. As discussed in the case of Town of Clarkstown v. Reeder (1983), the teacher exception provides that teachers and not the institution employing them own the copyright to their lectures and any writings based thereon, a finding that the court argued to be "compelled by the nature of our educational system" (Town of Clarkstown, p. 143 n.3). In the almost exclusively virtual days of the COVID-19 pandemic, it is to be noted, the instructor's copyright also does not transfer to the company that owns the means of the virtual technology that is used, even when that company is privately owned and not part of the educational setting itself, such as when Zoom and Microsoft Teams are relied upon. In fact, such internet companies are keen on emphasizing that as mere platforms of communications they do not claim copyright on content, thereby safeguarding them from any liabilities (Zoom 2020).

Fixation in terms of the 1976 Copyright Act applies to recordings of lectures with any kind of equipment and therefore also applies to current and future online technologies. The copyrights of taped lectures, virtual or otherwise, are explicitly protected by the 1976 Act, which states that a "work consisting of sounds, images, or both, that are being transmitted, is 'fixed' for purposes of this title if a fixation of the work is being made simultaneously with its transmission" (Title 17 $\S 102$ ). Attending a lecture as such does not automatically grant recording privileges. As the Code of Federal Regulations on Public Welfare specifies, students granted the right to tape lectures should "sign agreements that they will not release the tape recording or transcription or otherwise hinder the professor's ability to obtain a copyright" (Code of Federal Regulations, Title 45 Appendix A[a]). Schools and universities typically indeed require students who wish to tape 
lectures, even when they are granted such right on the basis of federal disability protections, to ask for and receive explicit permission from the instructor.

Federal regulations do not exhaust copyright protection inasmuch as the Copyright Act of 1976 allows for states to supplement the federal statute with other copyright provisions based on common law in order to fill any gaps not explicitly governed by the federal regulation (Nimmer and Nimmer 1978). Supplementing laws at the state level therefore could apply a stricter and more specific copyright that explicitly protects even unfixed works, including lectures in educational settings. As VerSteeg (1996) argues, an instructor is always "the 'author' of the lecture" and a state's common law may explicitly grant appropriate copyright regardless of fixation (p. 1354). The state of California, for instance, has extended copyright regulations by recognizing exclusive ownership rights in the representation or expression of "any original work of authorship that is not fixed in any tangible medium of expression" (California Code, Civil Code § 980).

Common law protection of lectures can additionally be guaranteed by developing university guidelines on the copyrights of lectures and/or by individual instructors assigning copyrights to their lectures and related materials. For instance, a copyright notice and prohibition of publishing beyond the (physical or virtual) classroom can be included in teaching syllabi to pertain to course notes and recordings of the lectures. University policy can further specify copyrightable works to include "tests, exams, class handouts, lesson plans, lectures and lecture notes, outlines, and educational units" (VerSteeg 1990, p. 414). The implications of lectures being copyrighted include that students can take notes and make recordings of the lectures they attend to prepare for exams and for private use related to their education. However, students would not be permitted to publish or sell their notes and/ or share authorized recordings of lectures in ways that intrude on the teacher's copyright.

Finally, activities involving students publishing notes and/ or distributing virtual recordings of lectures or parts thereof on the internet cannot live up to the standards of fair use as specified in the 1976 Copyright Act. In the 1976 federal act, fair use is mentioned to be allowed only upon consideration of four factors, relating to: (1) the purpose and character of the use; (2) the nature of the copyrighted work; (3) the amount and substantiality of the portion used; and (4) the effect of the use (Title $17 \S 107)$. Sharing notes or publishing recorded lectures wholesale, for profit or not, could on the basis of these considerations readily be argued to intrude upon instructor's copyright as benefits of the works are in effect transferred to others. Yet, as any one of the four statutory factors determining fair use alone is not decisive by itself, a judgment of fair use in any specific case can at best decide on the likelihood that use of a work was fair or not. Furthermore, as a fifth element, a transformation factor comes into play, to supersede any of the other four factors, when an original work is copied in novel or unexpected ways, such as in the case of parodies (Liu 2019). As with the four statutory factors of fair use, however, transformation is not intrinsically present but a matter subject to argumentation.

The fair use provision of the 1976 Copyright Act places great emphasis on the "amount and substantiality" of what is used from a copyrighted work. As the US Supreme Court has argued, "fragmentary words and phrases do not exhibit the minimal level of creativity necessary for copyright protection," while "[e]xtensive paraphrasing plainly constitutes copyright infringement" (Arica, pp. 1063, 1066). As information on the internet has long been held to be subject to copyright (Holmes and Levin 2000), sharing recorded lectures can virtually violate copyright as much as other forms of copying would by physical means. Moreover, the argument can be made that publicizing only selected phrases or sentences, when done for reasons not related to their original utterance, also constitutes a copyright violation precisely because its fragmentary nature changes the meaning of statements when taken out of the context of their educational setting. Trumping any transformation argument, this idea would also find support in the long-held judicial opinion that schools and universities are specific institutions with specific objectives in which conditions apply that are not present elsewhere.

\section{Beyond Copyright: Academic Freedom and Trust}

Apart from copyright, other legal avenues are available in US law that can provide safeguards to lectures on the basis of principles other than those justifying property rights in authored works. Among these are especially provisions related to academic freedom and breach of confidence.

Academic freedom refers to the free pursuit of knowledge and the right to unfettered inquiry and dissemination of knowledge, including the absence of restraints and pressures that inhibit the freedom of scholars to study, discuss, and publish ideas and opinions. Academic freedom is not only an important educational principle, it has also been recognized in the courts as protected under US law. In Sweezy v. New Hampshire (1957), for example, the US Supreme Court ruled that a college professor could not be compelled to testify about the content of his lectures on the grounds that the freedoms safeguarded by the Bill of Rights and the Fourteenth Amendment are essential in the community of universities. Chief Justice Warren justified the court's decision by stating: "The essentiality of freedom in the community of American universities is almost self-evident... Scholarship cannot flourish in an atmosphere of suspicion and distrust" (Sweezy, p. 250). 
Among the legal implications, the teacher exception to the copyright work-for-hire principle can be derived from the principle of academic freedom. As Dreyfuss (1987) argues on the basis Williams (1969), copyright applies in the academic community precisely because there are few if any commercial interests at stake as interests primarily pertain to the pursuit of knowledge. Grounded in academic freedom, instructors' copyright extend the "purely financial" to include "interests in the quality and integrity of the scholarly works" (pp. 592-593).

Arguing for the copyrightability of lectures in educational settings on the basis of academic freedom also makes sense on constitutional grounds, because copyright is mentioned in the US Constitution with explicit reference to scholarship and learning: "The Congress shall have power... [t]o promote the progress of science and useful arts, by securing for limited times to authors and inventors the exclusive right to their respective writings and discoveries" (US Constitution, article 1, section 8). The Supreme Court long ago affirmed that the constitutionally guaranteed copyright was expressly intended "for the encouragement of learning, and was not intended for the encouragement of mere industry, unconnected with learning and the sciences" (Clayton v. Stone \& Hall 1829).

Apart from supporting copyright, academic freedom can also be relied upon independently to protect instructor rights because the right relates to the constitutionally protected freedom of expression that is guaranteed by the First Amendment of the (federal) Constitution (Dreyfuss 1987; Meyer 1998). As such, impermissible interferences with the right to teach and the continued threat thereof might have a chilling effect (Dreyfuss 1987, p. 600). With the recent controversies surrounding instructors who have been sanctioned after fragments of their lectures had been unleashed on the internet, instructors can reasonably be expected to be curtailed in their speech for fear of accusations, however unwarranted. In these days of cancel culture, most problematically, these conditions can contribute to instructors engaging in self-censorship that negatively impact their teaching by limiting the content of their lectures (Chamlee-Wright 2019).

Another relevant right related to academic freedom is the privacy of instructors to determine autonomously how and what they teach and how related materials are presented to others (Rahimi 1995; Zimmerman 1992). The seminal paper on privacy by Samuel Warren and Louis Brandeis (1890) already recognized that privacy pertains to any kind of expression, no matter its form, and includes the right to publish. A perspective of academic freedom in terms of privacy and related publishing rights can be justified in view of the fact that teachers want to spread their knowledge as much as they can, but always and only in a manner they judge to be appropriate. Teachers have a stake in the educational merit and reputational interest that relies "on how the work is presented to the public" (Dreyfuss 1987, p. 605). Posting lectures or fragments thereof out of context on the internet without the teacher's permission would therefore violate academic freedom.

A possible downside to the discussed legal provisions to protect teaching is that they posit teachers in a potentially adversarial relationship with their students. As such, these strategies may be helpful, but they can never be more than necessary evils. To avoid the implied adversarial positioning of instructors and their students, the option can be suggested to protect teaching rights on the basis of breach of confidence or trust in terms of the special relationship that exists, and must exist, between teachers and students in a school or university. This option has the advantage of being practically attainable in the setting of the academic community and, additionally, of not having to rely on a separation between students and teachers, but instead presumes their mutual co-existence in an educational setting.

Breach of confidence or trust was, in fact, already a central principle in the Abernethy (1825) case in terms of the setting of the classroom in an educational institution. The judge in Abernethy referred to the fact that students attending the lectures had signed their name in a book to show classroom attendance and that they had paid a fee to attend (p. 1313). As such, the lectures were considered "not in any way open or accessible to the public" (p. 1315). The restricted and specific nature of the educational setting of teaching was also recognized in the 1976 Copyright Act when it specified fair use exceptions for teaching purposes in terms of "a classroom or similar place devoted to instruction" (Title $17 \S 110$ ). Recognizing the development of new technologies, as the Copyright Act explicitly does, this "similar place" will today also include virtual settings on the condition that they are "devoted to instruction" (ibid.).

Several legal experts have indeed suggested that breach of confidence can be applied to teaching. Dreyfuss (1987), for instance, argues that confidentiality in teaching is intrinsically implied by the educational relation that is established between student and instructor (Dreyfuss 1987, p. 634). As the judge in Abernethy already realized, such a provision on breach of confidence would hold "particularly where the contract is written" (Abernethy, p. 210). Thus, breach of confidence could be more easily invoked in the case of the distribution of recorded virtual lectures and fragments thereof when schools and universities have explicit policies in place that specify the mutual rights and responsibilities of instructors and students as matters of academic integrity. Similar to securing copyright, contracts guided by integrity and educational objectives, finally, can also be developed by individual instructors by detailing their pedagogical expectations and requirements for students registered in their classes, including specific statements about such expectations formalized in their course syllabi. 


\section{Law and Education as Idea and Praxis}

In view of several educationally problematic issues involved with the advent of the internet and, specifically, the widespread and relatively forced adoption of virtual methods of instruction during the COVID-19 pandemic, I have suggested several legal measures that can be relied upon to protect instructor rights. This paper, however, is not intended to defend a legalistic viewpoint that assumes that the legal issues concerning face-to-face and virtual teaching are exhaustive of their educational objectives and the broader normative dimensions that are involved. On the contrary, education can derive its fundamental merits only on pedagogically sound substantive grounds beyond any legalities. However, when judged necessary and educationally appropriate, the law can and should be used as an important and effective instrument to defend rights and principles by means of an authoritative protection of teaching against unapproved recordings and online distributions of lectures, whether they are delivered in the classroom or online.

In the context of applicable US law, copyrighting lectures, relying on instructors' right to academic freedom, and protecting trust between instructor and students can aid in securing educational objectives within an appropriate as well as constitutional framework. Copyright protections can be ensured based on the teacher exception to work-for-hire when lectures are considered fixed forms of expression, a condition that clearly pertains to lectures that are recorded during online distribution. Instructors' constitutionally protected academic freedom can be relied upon to grant copyright to lectures regardless of whether they are recorded or not or, independently thereof, to guarantee First Amendment protections of free speech. And breach of trust is involved in distributing unauthorized notes or transmitting recordings of lectures by virtue of an implied contract of trust or an explicitly written contract between students and teachers as specified by university policies and/or instructor guidelines in course syllabi.

This paper has focused on legal conditions that exist in the USA. Other national and international jurisdictions might not always be based on similar principles and may be more (or less) affected by supranational and international regulations, for example in the context of the European Union. Several relevant rights guaranteed by multiple levels of law, such as those concerning academic freedom, copyright, privacy, and defamation, may vary quite considerably and be comparatively stronger or weaker.

Besides jurisdictional variations and constitutional grounding, moreover, a number of practical questions remain, both in terms of pedagogy and with respect to law. As instructors, we are expected by our institutions to formally adjust course syllabi to appropriate governing laws, for instance by inclusion of statements to accommodate students with disabilities and on matters that pertain to (anti-)harassment and (non-)discrimination. The new realities of online teaching, during and after the COVID-19 pandemic, could justify additional adjustments of course syllabi, such as by inclusion of formal expectations on proper lecture attendance and instructor and students rights and responsibilities. Whichever form such provisions might take, however, technological and cultural changes will still affect how and what instructors will teach, not on the basis of their expertise, but out of fear for the reprisals they might face. In view of what has happened to some instructors in the current climate, from facing public shaming and institutional reprimands to a loss of employment, such fears are not irrational.

Teaching takes place in the context of formally organized institutions in which instructors are legally employed. They are thereby confronted with the organizational power of educational settings to specify the terms of their contracts. In today's competitive climate created by an overproduction of graduate degrees, for instance, universities have much more leeway to determine the conditions of faculty employment, including the relative share of research and teaching duties (to wit the drift towards hiring full-time faculty with exclusive teaching responsibilities), and, indeed, a determination of what constitutes work for hire. The implicit understanding of a teacher exception to the work-for-hire provision in the 1976 Copyright Act might therefore have to be formalized, either by (state or federal) law or, at an institutional level, by instructors securing such rights explicitly in school and university policies. Either individually or collectively through intermediate groups representing instructors, that task might not be an easy one. By example, in a recent case involving attempts to compel teachers in California to engage in synchronous online teaching or record lessons for later use, school districts found themselves at odds with the California Teachers Association, which invoked a state law that prohibits unauthorized recordings of lectures on the grounds that they disrupt and impair the teaching process (Fensterwald 2020). The counter-argument was made by lawyers representing the school districts that lecture recordings cannot be disruptive to teaching except in physical settings, thereby totally overlooking the impact of such recordings being transmitted online after a lecture's original delivery and outside of its original educational settings. Moreover, as with all spheres of law, even when legal provisions are available, difficult issues of access-to-justice remain, ranging from the cost of invoking legal and/or institutional norms to what can be practically achieved after reputational harm has already been brought about, especially on the internet.

Questions of enforcement of laws and relevant policies are important to be considered as well. Both instructors and students have rights and responsibilities, no matter if copyright, academic freedom, or breach of trust is involved. Any issues or infractions, however, should ideally first be addressed within the educational setting itself before any external legal 
mechanisms are invoked. Legitimate student concerns regarding an instructor's teaching and lecture style or content, for instance, can be relayed (anonymously or not) to the instructor or, in accordance with institutional regulations, passed on to relevant authorities within the school or university. By contrast, when a recorded lecture or fragment thereof is made publicly available without permission by being posted on any of the internet's popular social networking sites, that practice itself will function as a form of punishment, because reputational and professional harm will be difficult, if not impossible to avoid. Under such problematic circumstances, invoking the law and other formal rules may not only be allowed but morally just as well.

It should be obvious that suing students over legal infractions related to teaching is a far from ideal situation. But it is also true that the technologies of the internet, along with the current climate of safe spaces and cancel culture, present new challenges that are potentially problematic on so many levels that without formal and sanctionable rules, enacted by legislators or formalized by educational institutions and/or individual instructors, continued problems will occur. It is conversely equally true that with appropriate legislative and judicial measures in place and with clear university policies and a specification of expectations that are respectful of instructor and student rights and duties alike, legal protections can be applied when necessary in an environment that remains committed to the essence of education in our society.

\section{Further Reading}

Abernethy v. Hutchinson, 47 Eng. Rep. 1313 (1825).

Arica Institute, Inc. v. Palmer, 761 F. Supp. 1056 (1991).

Borow, Todd A. 1998. Copyright ownership of scholarly works created by university faculty and posted on school-provided web pages. University of Miami Business Law Review, 7, 149-169.

Bultman, Matthew. 2020. Online teaching during pandemic raises copyright concerns. Bloomberg Law, April 3, 2020. https://news. bloomberglaw.com/ip-law/online-teaching-amid-virus-raisescopyright-questions

California Code, Civil Code $\S 980$. https://codes.findlaw.com/ca/civilcode/civ-sect-980.html

Chamlee-Wright, Emily. 2019. Self-censorship and associational life in the liberal academy. Society, 56, 538-549.

Clayton et al. v. Stone et al., 5 F. Cas. 999 (1829).

Code of Federal Regulations, Title 45: Public Welfare. https://www. govinfo.gov/content/pkg/CFR-2017-title45-vol1/xml/CFR-2017title45-vol1-part84.xml

Cohen, Andrew J. 2017. Psychological harm and free speech on campus. Society, 54, 320-325.

Conklin, Audrey. 2020. Teachers, students using zoom for e-learning see alarming behavior on platform. Fox Business, August 21, 2020. https://finance.yahoo.com/news/teachers-students-using-zoom-e203008428.html
Copyright Act of 1909, 35 Stat. 1075-88, 17 U.S.C. $\S \S 1-216$ (repealed 1978). https://www.kasunic.com/1909 act.htm

Copyright Act of 1976, 17 U.S.C. $\S \S 101-1401$. https://www.copyright. gov/title17/AppendixA.pdf

Deflem, Mathieu. 2000. Dot-coms in our lecture halls. Harvard Crimson, March 9, 2000. https://www.thecrimson.com/article/2000/3/9/dotcoms-in-our-lecture-halls-pharvard/

Deflem, Mathieu. 2008. Sociology of Law: Visions of a Scholarly Tradition. Cambridge: Cambridge University Press.

Dreyfuss, Rochelle C. 1987. The creative employee and the Copyright Act of 1976. University of Chicago Law Review, 43, 590-647.

Fensterwald, John. 2020. Some teachers unions, districts at odds over live distance learning instruction. EdSource, July 2, 2020. https:// edsource.org/2020/some-teachers-unions-districts-at-odds-overlive-distance-learning-instruction/635237

Flaherty, Colleen. 2020. Failure to communicate: Professor suspended for saying a Chinese word that sounds like a racial slur in English. Inside Higher Ed, September 8, 2020. https://www.insidehighered. com/news/2020/09/08/professor-suspended-saying-chinese-wordsounds-english-slur

Hays v. Sony Corporation of America, 847 F.2d. 412 (1988).

Holmes, Georgia, and Daniel A. Levin. 2000. Who owns course materials prepared by a teacher or professor? The application of copyright law to teaching materials in the internet age. Brigham Young University Law Review, 2000, 165-189.

Hutchinson Kristine H. 2003. The Teach Act: Copyright law and online education. New York University Law Review, 78(6), 2204-2240.

International News Service v. The Associated Press, 248 U.S. 215 (1918).

King v. Mister Maestro, 224 F. Supp. 101 (1963).

Le Moal-Gray, Michele J. 2016. Distance education and intellectual property: The realities of copyright law and the culture of higher education copyright law and the culture of higher education. Touro Law Review, 16, 981-1035.

Liu, Jiarui. 2019. An empirical study of transformative use in copyright law. Stanford Technology Law Review, 22, 163-241.

Meyer, Mark L. 1998. To promote the progress of science and useful arts: The protection of and rights in scientific research. IDEA: The Journal of Law and Technology, 39, 1-34.

Miles Medical Company v. Park \& Sons, 220 U.S. 373 (1911).

Miller, Joshua R. 2020. Pennsylvania professor fired for repeatedly using n-word during Zoom session. New York Post, October 8, 2020. https://nypost.com/2020/10/08/pennsylvania-professor-fired-forusing-n-word-during-lecture/

Needham, J. Boddie, McThenia, Thomas C., Amos, Fred B., and Douglas W. Kim. 1998. A review of copyright and the internet. Campbell Law Review, 20, 193-272.

Nimmer, David, and Melville B. Nimmer. 1978. Nimmer on Copyright. New York: M. Bender.

Public Affairs Associates v. Rickover, 369 U.S. 111 (1962).

Rahimi, Todd J. 1995. The power to control identity: Limiting a celebrity's right to publicity. Santa Clara Law Review, 35, 725-753.

Sherrill v. Grieves, 57 Wash. L. Rep. 286, 20 C.O. Bull. 675 (1929).

Steinbuch, Yaron. 2021. California teacher suspended for berating students during Zoom class. New York Post, April 13, 2021. https:// nypost.com/2021/04/13/california-teacher-suspended-for-beratingstudents/

Sweezy v. New Hampshire, 354 U.S. 234 (1957).

VerSteeg, Russ. 1990. Copyright and the educational process: The right of teacher inception. Iowa Law Review, 75, 381-416.

VerSteeg, Russ. 1996. Defining 'author' for purposes of copyright. American University Law Review, 45, 1323-1366.

Vincent, James. 2020. University staff are worried their recorded lectures will be used against them: When lectures go online, who gets to keep the copyright? The Verge, August 20, 2020. https://www.theverge. 
com/21373669/recorded-lecture-capture-copyright-universitiescoronavirus-fears

Warren, Samuel D. and Louis D. Brandeis. 1890. The right to privacy. Harvard Law Review, 4, 193-220.

Williams v. Weisser, 273 Cal. App. 2 d 726 (1969).

Zimmerman, Diane L. 1992. Information as speech, information as goods: Some thoughts on marketplaces and the bill of rights. William and Mary Law Review, 33, 665-740.

Zoom. 2020. "Zoom Terms of Service" (Effective: August 20, 2020). https://zoom.us/terms
Publisher's Note Springer Nature remains neutral with regard to jurisdictional claims in published maps and institutional affiliations.

Mathieu Deflem is Professor of Sociology at the University of South Carolina. His specialty areas include sociology of law, popular culture, internet technology, and social theory. He is the author of four books, including Sociology of Law (Cambridge University Press, 2008), and editor or co-editor of multiple volumes, including Media and Law: Between Free Speech and Censorship (Emerald Publishing, 2021). 